\title{
Microcalorimetric Study of Aqueous Solution of a Thermoresponsive Polymer, poly( $N$-vinylisobutyramide) (PNVIBA)
}

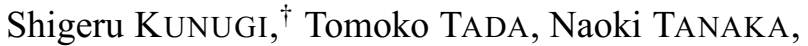 \\ Kazuya YAmAмото, ${ }^{*}$ and Mitsuru AKASHI* \\ Department of Polymer Science and Engineering, Kyoto Institute of Technology, \\ Matsugasaki, Sakyo, Kyoto 606-8585, Japan \\ *Department of Applied Chemistry, Kagoshima University, \\ Koorimoto, Kagoshima 890-0065, Japan
}

(Received March 4, 2002; Accepted April 3, 2002)

\begin{abstract}
A temperature-responsive synthetic vinyl polymer with hydrogen-bonding and hydrophobic side residues, poly( $N$-vinylisobutyramide) (PNVIBA), was studied for its calorimetric properties in aqueous solutions. The temperature-responsive behavior was dependent on the polymer concentration at lower range and also on the concentration of added sodium dodecyl sulfate (SDS) at higher range. Thermodynamic parameters and molecular weight dependence were discussed in comparison with the corresponding results from poly( $N$-isopropylacrylamide) (PNIPAM).

KEY WORDS Thermoresponsive Polymer / Poly $(N$-isopropylacrylamide $) / \operatorname{Poly}(N$-vinylisobutyramide) / Sodium Dodecylsulfate / Microcalorimetry / Thermodynamics /
\end{abstract}

Several synthetic vinyl polymers with both hydrogen bonding and hydrophobic properties are known to show changes in their molecular level states (in solution) and volume phase transitions (in gel form) in aqueous media, responding to the changes of the environmental factors such as temperature. Poly( $N$-isopropylacrylamide) (PNIPAM) and other poly(acrylamide) derivatives are the best known examples. ${ }^{1-3}$ These polymers show sharp reversible transitions from extended (coil) state to compact (collapse) state in solution, upon a change in temperature. Several applications such as drug delivery, immobilization of enzymes, and bioseparation have been studied by taking advantage of these characteristic temperatureresponsive properties. ${ }^{4-6}$

Some of the poly(vinylamine) derivatives, such as poly( $N$-vinylisobutyramide) (PNVIBA), also show distinct thermoresponsive properties, ${ }^{7-9}$ and we have studied the effects of pressure, salt, and surfactants on them, and compared with those of poly(acrylamide) derivatives. $^{10-13}$

PNVIBA and PNIPAM have the side chain amide bonds in inverted directions. Both are isomers of polyleucine and can be considered as a simple but relevant model of proteins. ${ }^{14,15}$ The negative heat capacity changes $\left(\Delta C_{\mathrm{p}}\right)$ upon transition observed for these polymers have been discussed with relation to the cold denaturation of proteins, ${ }^{16}$ and their characteristic elliptic temperature-pressure transition diagrams have been considered to give a general idea of protein denaturations induced by high hydrostatic pressures. ${ }^{17}$
PNVIBA has many similarities to PNIPAM, but also shows some differences, such as transition sharpness and higher transition temperature $\left(T_{\mathrm{t}}\right)$ and pressure $\left(P_{\mathrm{t}}\right)$. In this report, we studied the calorimetric properties of PNVIBA in aqueous solutions by using a high-sensitive differential scanning calorimeter (DSC), as for the polymer concentration dependence, effects of SDS addition, and molecular weight dependence. The results were compared with the corresponding results of poly ( $N$-isopropylacrylamide) (PNIPAM) solution, from our own and reported sources. ${ }^{14,15,18}$

\section{EXPERIMENTAL}

\section{Materials}

Homopolymers of PNVIBA were synthesized as described previously ${ }^{7}$ and chromatographically fractionated. Their molecular weights and molecular weight distributions were determined by GPC [Shodex AD$80 \mathrm{M} / \mathrm{S}$ or TSK-gel super-H 3000 and 4000 columns with a DMF solution (containing $10 \mathrm{mM} \mathrm{LiBr}$ )]. $M_{\mathrm{n}}$ values indicated below are based on the commercial PEG-PEO standards. The GPC equipment was a Tosoh HLC-8120 GPC or a Shimadzu LC10A system with an RI detector. Three samples of PNVIBA $\left(M_{\mathrm{n}}=11 \mathrm{kDa}\right.$ and $M_{\mathrm{w}} / M_{\mathrm{n}}=1.4, M_{\mathrm{n}}=66 \mathrm{kDa}$ and $M_{\mathrm{w}} / M_{\mathrm{n}}=1.6$, and $M_{\mathrm{n}}=460 \mathrm{kDa}$ and $\left.M_{\mathrm{w}} / M_{\mathrm{n}}=2.4\right)$ and one sample of PNIPAM $\left(M_{\mathrm{n}}=49 \mathrm{kDa}\right.$ and $M_{\mathrm{w}} / M_{\mathrm{n}}=$ 1.8) were studied. ${ }^{12}$ Sodium dodecyl sulfate (SDS) and other chemical reagents were purchased from Nacalai Tesque (Kyoto, Japan) or Wako Pure Chemicals (Os-

${ }^{\dagger}$ To whom correspondence should be addressed (Tel: +81-75-724-7836, Fax: +81-75-724-7800, E-mail: kunugi@ipc.kit.ac.jp). 
aka, Japan).

\section{Methods}

DSC measurements were performed by a highsensitive DSC meter, Nano-DSC II Model 6100 (Calorimetry Science Co., UT, USA). About $0.3 \mathrm{~mL}$ of an aqueous solution of polymer was introduced to the sample tube of the apparatus and the temperaturescanning rate was usually $1 \mathrm{~K} \mathrm{~min}^{-1}$. The effects of scanning rate on the obtained thermodynamic parameters were preliminary tested and checked. The parameters obtained from these DSC measurements were calculated on the base of polymer molarity and the $M_{\mathrm{n}}$ was used for the calculations. The van't Hoff enthalpy $\left(\Delta H^{\mathrm{vH}}\right)$ was approximately calculated with the following equation. ${ }^{14,19}$

$$
\Delta H^{\mathrm{vH}}=4 R T_{\mathrm{p}}^{2}\left(C_{\mathrm{p} \max } / \Delta H\right),
$$

where $T_{\mathrm{p}}, C_{\mathrm{p} \max }$ and $\Delta H$ are the peak temperature, maximum $C_{\mathrm{p}}$, and enthalpy change of transition as integrated form the thermogram, respectively. The cooperative number $(n)$ is the ratio of $\Delta H$ and $\Delta H^{\mathrm{vH}}$ and indicates the (average) number of cooperative units or domains in one polymer molecule.

\section{RESULTS}

\section{Polymer Concentration Dependence}

The thermograms observed for various concentrations of PNVIBA $\left(M_{\mathrm{n}}=11 \mathrm{kDa}\right)$ are shown in Figure 1. PNVIBA of other molecular weighs gave fundamentally similar thermograms. The $T_{\mathrm{t}}$ observed at $0.04(\mathrm{w} / \mathrm{v}) \%\left(41.7^{\circ} \mathrm{C}\right)$ was almost identical with that observed in turbidimetry. ${ }^{12}$ With diluting polymer solutions, the endothermic peak shifted slightly to the higher temperature and the peak was $45.0^{\circ} \mathrm{C}$ at 0.001 $(\mathrm{w} / \mathrm{v}) \%$, though the thermogram was rather noisy with such a low concentration of polymer. The thermodynamic parameters calculated from these and other thermograms are compiled in Table I, together with the corresponding results from PNIPAM $\left(M_{\mathrm{n}}=49 \mathrm{kDa}\right)$. As reported before, ${ }^{12,15}$ polymers with smaller molecular weight showed higher transition temperature. Both $\Delta H$ and $\Delta S$ of transition increased with increasing polymer concentration. The van't Hoff enthalpy $\left(\Delta H^{\mathrm{vH}}\right)$ and hence the cooperative number $\left(n=\Delta H / \Delta H^{\mathrm{vH}}\right)$ showed some specific values at the lowest concentration, probably due to the lower quality of the thermograms at such low concentrations, but they did not show significant concentration dependence. To compare the thermodynamic values obtained for polymers of different $M_{\mathrm{n}}$, the concentration dependence of $\Delta H$ and $\Delta S$ per monomer unit ( $\Delta H_{\text {monomer }}$ and $\Delta S_{\text {monomer }}$ ) are shown in Figure 2,

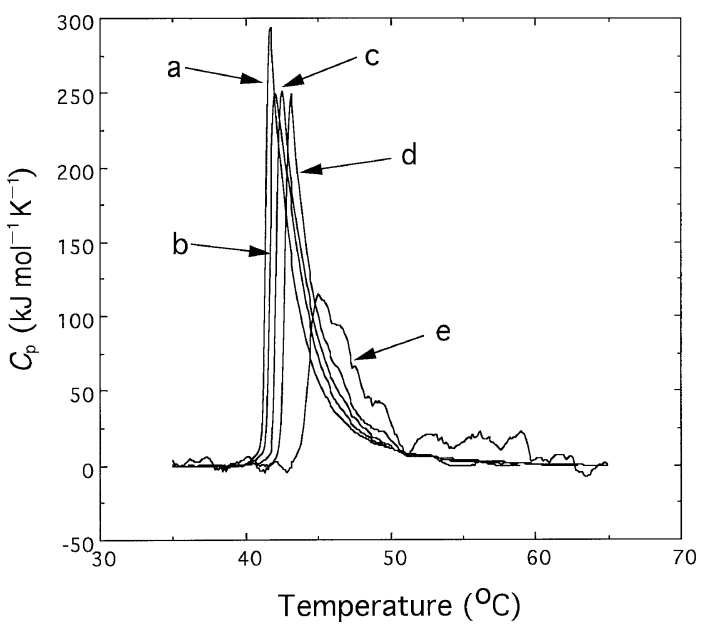

Figure 1. DSC thermograms for various concentrations of PNVIBA aqueous solutions. Polymer concentrations $((\mathrm{w} / \mathrm{v}) \%)$ : a, 0.04; b, 0.02; c, 0.01; d, 0.005; e, 0.001. Scanning rate; $1 \mathrm{~K} \mathrm{~min}{ }^{-1}$.

together with $T_{\mathrm{t}}$ and cooperative monomer number $\left(n_{\mathrm{m}}\right.$ $=[$ degree of polymerization (DP) $] / n$; denotes the (average) number of monomer units involved in one cooperative unit or domain). The concentration dependence of $T_{\mathrm{t}}, \Delta H_{\text {monomer }}$ and $\Delta S_{\text {monomer is larger for shorter poly- }}$ mers, although the values of latter two were not aligned with the $M_{\mathrm{n}}$ values. For the polymer of the highest $M_{\mathrm{n}}$, the concentration dependence was rather small. The shift in $T_{\mathrm{t}}$ for PNIPAM was comparable to PNBIVA, but those for $\Delta H_{\text {monomer }}$ and $\Delta S_{\text {monomer were larger for }}$ PNIPAM and they were well compensated to show very small shift in $T_{\mathrm{t}}$. About 400 monomer units are involved in one cooperative domain of collapse transition, except for the shortest polymer, where around 200 monomer units composed a cooperative domain, which corresponds to two polymer chains.

The $\Delta C_{\mathrm{p}}$ values for PNVIBA and PNIPAM were always negative. By this fact, the transitions of these and other thermoresponsive polymers are considered as a good model of the cold denaturation of proteins. ${ }^{14-17}$ Usually $C_{\mathrm{p}}$ values are lower in the native structures of proteins and both thermal and cold denaturation bring about an increase in $\Delta C_{\mathrm{p}}$; as a result the inverse process of so-called cold denaturation (changes caused by increasing temperature from the cold-denatured state) is associated with a negative $\Delta C_{\mathrm{p}}{ }^{16}$

\section{Effects of SDS Addition}

The thermograms of PNVIBA $\left(M_{\mathrm{n}}=11 \mathrm{kDa}\right)$ solutions in the presence of various concentrations of SDS are shown in Figure 3. It has been understood that a surfactant like SDS at low concentrations does little affect $T_{\mathrm{t}}$ but only hinders the successive aggregations of collapsed chains. Actually we and other researchers have shown that, as far as turbidimetric measurements are 
Table I. Parameters obtained by DSC measurement of PNVIBA and PNIPAM solutions ${ }^{\mathrm{a}}$

\begin{tabular}{|c|c|c|c|c|c|c|c|c|}
\hline Polymer & $\frac{M_{\mathrm{n}}}{\mathrm{kDa}}$ & $\frac{\text { conc. }}{(\mathrm{w} / \mathrm{v}) \%}$ & $\frac{T_{\mathrm{t}}}{{ }^{\circ} \mathrm{C}}$ & $\frac{\Delta H}{\mathrm{~kJ} \mathrm{~mol}^{-1}}$ & $\frac{\Delta H^{\mathrm{VH}}}{\mathrm{kJ} \mathrm{mol}}$ & $\frac{\Delta S}{\mathrm{~kJ} \mathrm{~K}^{-1} \mathrm{~mol}^{-1}}$ & $\frac{\Delta C_{\mathrm{p}}}{\mathrm{kJ} \mathrm{K}^{-1} \mathrm{~mol}^{-1}}$ & $n^{\mathrm{b}}$ \\
\hline \multirow[t]{15}{*}{ PNVIBA } & \multirow[t]{5}{*}{11} & 0.001 & 45.0 & 616.8 & 245 & 1.939 & -2.6 & 2.5 \\
\hline & & 0.005 & 43.1 & 682.5 & 1496 & 2.158 & -6.6 & 0.46 \\
\hline & & 0.01 & 42.5 & 714.4 & 1351 & 2.263 & -9.9 & 0.53 \\
\hline & & 0.02 & 42.0 & 764.4 & 1112 & 2.426 & -11 & 0.69 \\
\hline & & 0.04 & 41.7 & 766.3 & 1415 & 2.434 & -16 & 0.54 \\
\hline & \multirow[t]{5}{*}{66} & 0.001 & 41.7 & 4412 & 5468 & 14.01 & -211 & 0.81 \\
\hline & & 0.005 & 41.3 & 4650 & 3734 & 14.79 & -22 & 1.2 \\
\hline & & 0.01 & 41.1 & 4792 & 3548 & 15.25 & -71 & 1.4 \\
\hline & & 0.02 & 40.9 & 4807 & 3634 & 15.31 & -73 & 1.3 \\
\hline & & 0.04 & 40.8 & 4859 & 3633 & 15.48 & -74 & 1.3 \\
\hline & \multirow[t]{5}{*}{460} & 0.001 & 40.2 & 27252 & 5754 & 86.97 & -413 & 4.7 \\
\hline & & 0.005 & 39.9 & 27991 & 2840 & 89.41 & -448 & 9.9 \\
\hline & & 0.01 & 39.7 & 28144 & 2677 & 89.96 & -500 & 10.5 \\
\hline & & 0.02 & 39.6 & 28274 & 2874 & 90.40 & -513 & 9.8 \\
\hline & & 0.04 & 39.4 & 28348 & 3169 & 90.70 & -515 & 8.9 \\
\hline \multirow[t]{5}{*}{ PNIPAM } & \multirow[t]{5}{*}{49} & 0.001 & 37.0 & 1873 & 1671 & 6.040 & -8.9 & 1.1 \\
\hline & & 0.005 & 36.4 & 2339 & 1926 & 7.555 & -11.9 & 1.2 \\
\hline & & 0.01 & 36.4 & 2426 & 2010 & 7.838 & -12.4 & 1.2 \\
\hline & & 0.02 & 36.3 & 2499 & 2019 & 8.074 & -13.5 & 1.2 \\
\hline & & 0.04 & 36.2 & 2736 & 1916 & 8.846 & -19.3 & 1.4 \\
\hline
\end{tabular}

${ }^{\mathrm{a}}$ Thermodynamic parameters were calculated based on polymer mole using $M_{\mathrm{n}}$ values. ${ }^{\mathrm{b}} n=\Delta H / \Delta H^{\mathrm{vH}}$.
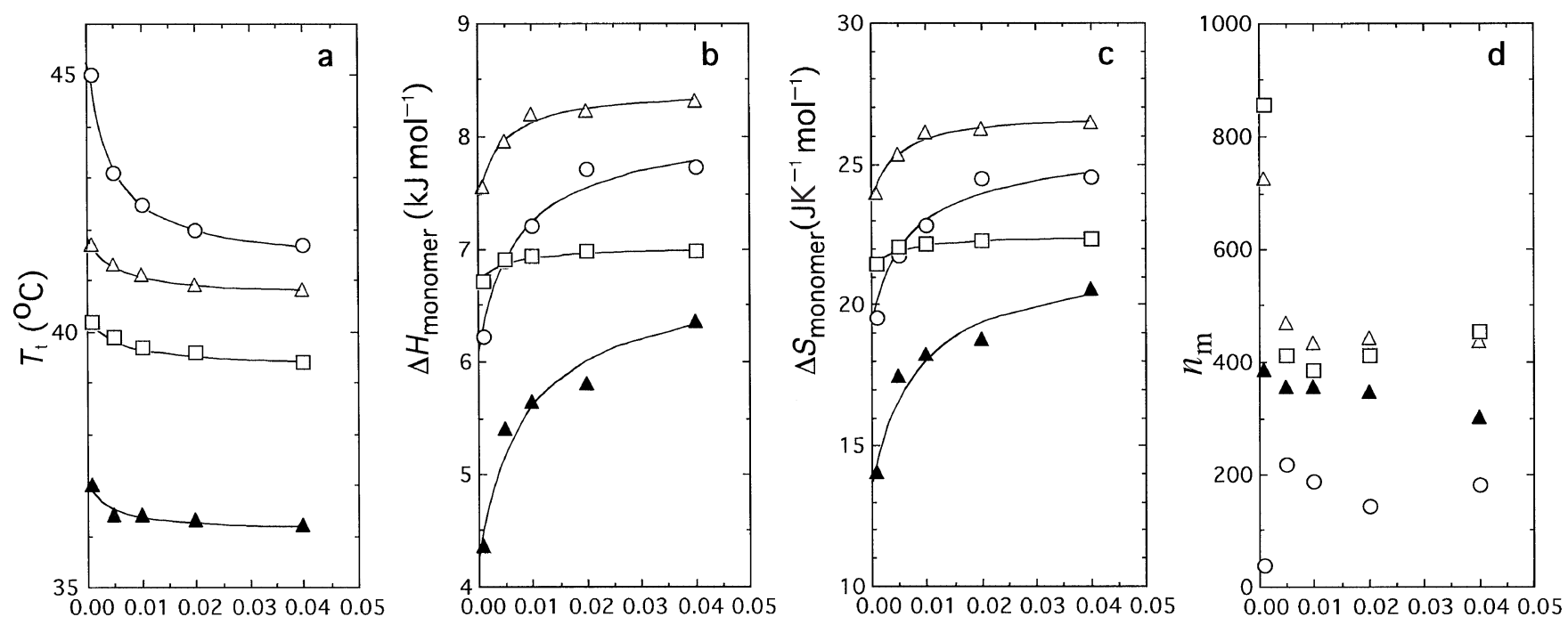

Polymer Concentration (\%)

Figure 2. Polymer concentration dependence of $T_{\mathrm{t}}$ (a), $\Delta H_{\text {monomer }}$ (b), $\Delta S_{\text {monomer }}$ (c), and $n_{\mathrm{m}}$ (d) for PNVIBA and PNIPAM solutions. PNVIBA: $\bigcirc, M_{\mathrm{n}}=11 \mathrm{kDa}: \triangle, M_{\mathrm{n}}=66 \mathrm{kDa}: \square, M_{\mathrm{n}}=460 \mathrm{kDa}$. PNIPAM: $\Delta, M_{\mathrm{n}}=49 \mathrm{kDa}$. Curves were drawn on an assumption of a simple saturation (hyperbolic) function.

concerned, the apparent $T_{\mathrm{t}}$ did not show distinct change with addition of SDS up to $c a$. $0.03(\mathrm{w} / \mathrm{v}) \%$. Therefore, this technique was applied for the dynamic light scattering measurements, in order to prevent turbidity, for the measurement of the collapsed (single) chain size. ${ }^{10,12,14,20}$ Actually, SDS addition up to $0.02 \%$ concentration showed very small shift in $T_{\mathrm{t}}$ or even slightly lowered it.
The thermodynamic parameters calculated from these and other thermograms for PNVIBA and PNIPAM are compiled in Table II. The critical micelle concentration of SDS around room temperature is known to be about $8 \mathrm{mM}(c a .0 .23(\mathrm{w} / \mathrm{v}) \%)$. Even well below this value, however, addition of, e.g., 0.05 or $1(\mathrm{w} / \mathrm{v}) \%$ SDS drastically shifted $T_{\mathrm{t}}$. No distinct $C_{\mathrm{p}}$ peaks were observed for simple aqueous solutions of SDS at this 
Table II. Effects of SDS addition on the DSC parameters of PNVIBA and PNIPAM solutions ${ }^{\mathrm{a}}$

\begin{tabular}{|c|c|c|c|c|c|c|c|c|}
\hline Polymer & $\frac{M_{\mathrm{n}}}{\mathrm{kDa}}$ & $\frac{\text { SDS conc. }}{(\mathrm{w} / \mathrm{v}) \%}$ & $\frac{T_{\mathrm{t}}}{{ }^{\circ} \mathrm{C}}$ & $\frac{\Delta H}{\mathrm{~kJ} \mathrm{~mol}^{-1}}$ & $\frac{\Delta \mathrm{S}}{\mathrm{kJ} \mathrm{K}^{-1} \mathrm{~mol}^{-1}}$ & $\frac{\Delta H^{\mathrm{VH}}}{\mathrm{kJ} \mathrm{mol}^{-1}}$ & $\frac{\Delta C_{\mathrm{p}}}{\mathrm{kJ} \mathrm{K}^{-1} \mathrm{~mol}^{-1}}$ & $n$ \\
\hline \multirow[t]{15}{*}{ PNVIBA } & \multirow[t]{5}{*}{11} & 0 & 42.5 & 714.4 & 2.34 & 1351 & -9.9 & 0.53 \\
\hline & & 0.005 & 42.1 & 634.6 & 2.01 & 1384 & -3.6 & 0.45 \\
\hline & & 0.02 & 43.5 & 524.1 & 1.66 & 1222 & -7.2 & 0.43 \\
\hline & & 0.05 & 50.7 & 409.6 & 1.27 & 1602 & -7.4 & 0.26 \\
\hline & & 0.1 & 60.5 & 382.6 & 1.15 & 1497 & -13.1 & 0.26 \\
\hline & \multirow[t]{5}{*}{66} & 0 & 41.1 & 4792 & 15.3 & 3548 & -70.9 & 1.35 \\
\hline & & 0.005 & 40.8 & 4503 & 14.3 & 2795 & -72.0 & 1.61 \\
\hline & & 0.02 & 41.9 & 3661 & 11.6 & 1206 & -61.7 & 3.04 \\
\hline & & 0.05 & 44.1 & 2555 & 8.05 & 1124 & -30.3 & 2.27 \\
\hline & & 0.1 & 50.8 & 2490 & 7.69 & 891 & -19.6 & 2.79 \\
\hline & \multirow[t]{5}{*}{460} & 0 & 39.7 & 27678 & 88.5 & 2722 & -500 & 10.2 \\
\hline & & 0.005 & 38.6 & 24541 & 78.7 & 1963 & -195 & 12.5 \\
\hline & & 0.02 & 38.5 & 22365 & 71.8 & 1187 & -477 & 18.8 \\
\hline & & 0.05 & 40.2 & 17816 & 56.9 & 1219 & -456 & 14.6 \\
\hline & & 0.1 & 45.6 & 15924 & 50.0 & 1316 & -449 & 12.1 \\
\hline \multirow[t]{5}{*}{ PNIPAM } & \multirow[t]{5}{*}{49} & 0 & 36.4 & 2426 & 7.84 & 2010 & -12.4 & 1.21 \\
\hline & & 0.005 & 36.5 & 2405 & 7.77 & 1785 & -10.3 & 1.35 \\
\hline & & 0.02 & 36.5 & 2364 & 7.64 & 1525 & -19.2 & 1.55 \\
\hline & & 0.05 & 40.7 & 2310 & 7.36 & 2166 & -17.4 & 1.07 \\
\hline & & 0.1 & 51.3 & 2284 & 7.04 & 1880 & -16.0 & 1.22 \\
\hline
\end{tabular}

${ }^{a}$ Thermodynamic parameters were calculated based on polymer mole using $M_{\mathrm{n}}$ values. [Polymer] $=0.01(\mathrm{w} / \mathrm{v}) \%$.

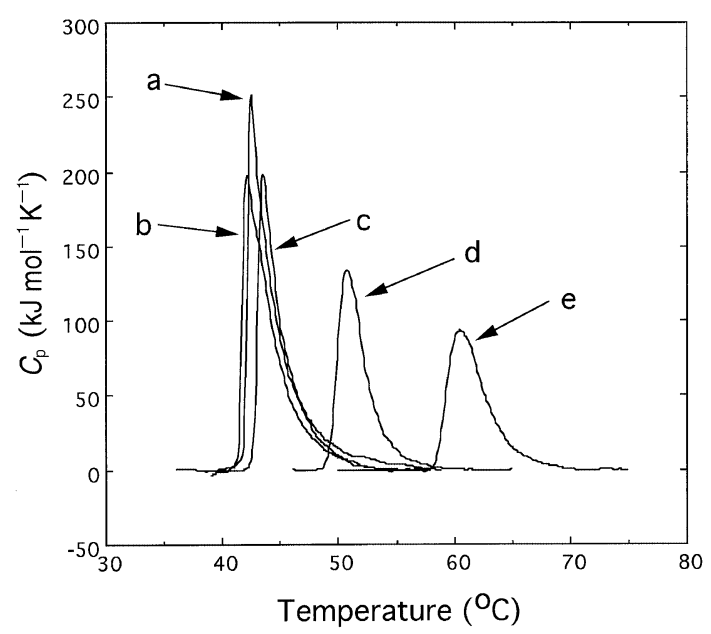

Figure 3. DSC thermograms for PNVIBA aqueous solutions in the presence of various concentrations of SDS. SDS concentrations $((\mathrm{w} / \mathrm{v}) \%): \mathrm{a}, 0 ; \mathrm{b}, 0.005 ; \mathrm{c}, 0.02 ; \mathrm{d}, 0.05 ; \mathrm{e}, 0.1$. Scanning rate; $1 \mathrm{~K}$ $\min ^{-1}$.

concentration level. Both $\Delta H$ and $\Delta S$ of transition decreased with increasing SDS concentrations. The concentration dependence of $\Delta H_{\text {monomer }}$ and $\Delta S_{\text {monomer }}$ are shown in Figure 4, in order to compare the thermodynamic values obtained for polymers of different $M_{\mathrm{n}}$, together with $T_{\mathrm{t}}$ and $n_{\mathrm{m}}$. The concentration dependence of $T_{\mathrm{t}}$ is larger for shorter PNVIBA, and that of $\Delta H_{\text {monomer }}$ and $\Delta S_{\text {monomer }}$ were larger in PNVIBA than in PNIPAM. Changes in $n_{\mathrm{m}}$ are rather scattered, ranging between 200-400 monomer units, but the effects seemed to be larger for shorter polymers.

\section{DISCUSSION}

Microcalorimetric studies ${ }^{13-15,18,21-23}$ and dynamic light scattering studies ${ }^{12,24-27}$ on thermoresponsive vinyl polymers in dilute solutions have indicated that these polymers showed a coil-collapse change as a single molecular event at the same temperature as detected by the cloud point measurement. The changes are not driven by the aggregation of collapsed chains, but the visible changes occur as a successive result of the formation of the collapsed chains. For long polymers, changes occur at several cooperative domains in a single chain, and, for short polymers, association of some chains seems to be necessary in order to perform the observable change.

Even for the well-fractionated preparations of polymers as in the present study, the molecular weight distribution is still significant, when compared with those of proteins. However, the size of cooperative domain, as determined by the ratio of $\Delta H / \Delta H^{\mathrm{vH}}$, has significant meaning when we compare the samples of significant differences in their molecular weight. The all-or-none coil-collapse transition ${ }^{25}$ of these vinyl polymers occurs at about 400 monomer units in a polymer chain. Although the present shortest sample gave $n_{\mathrm{m}} \sim 200$, it is still larger than the mean DP for this sample, and 

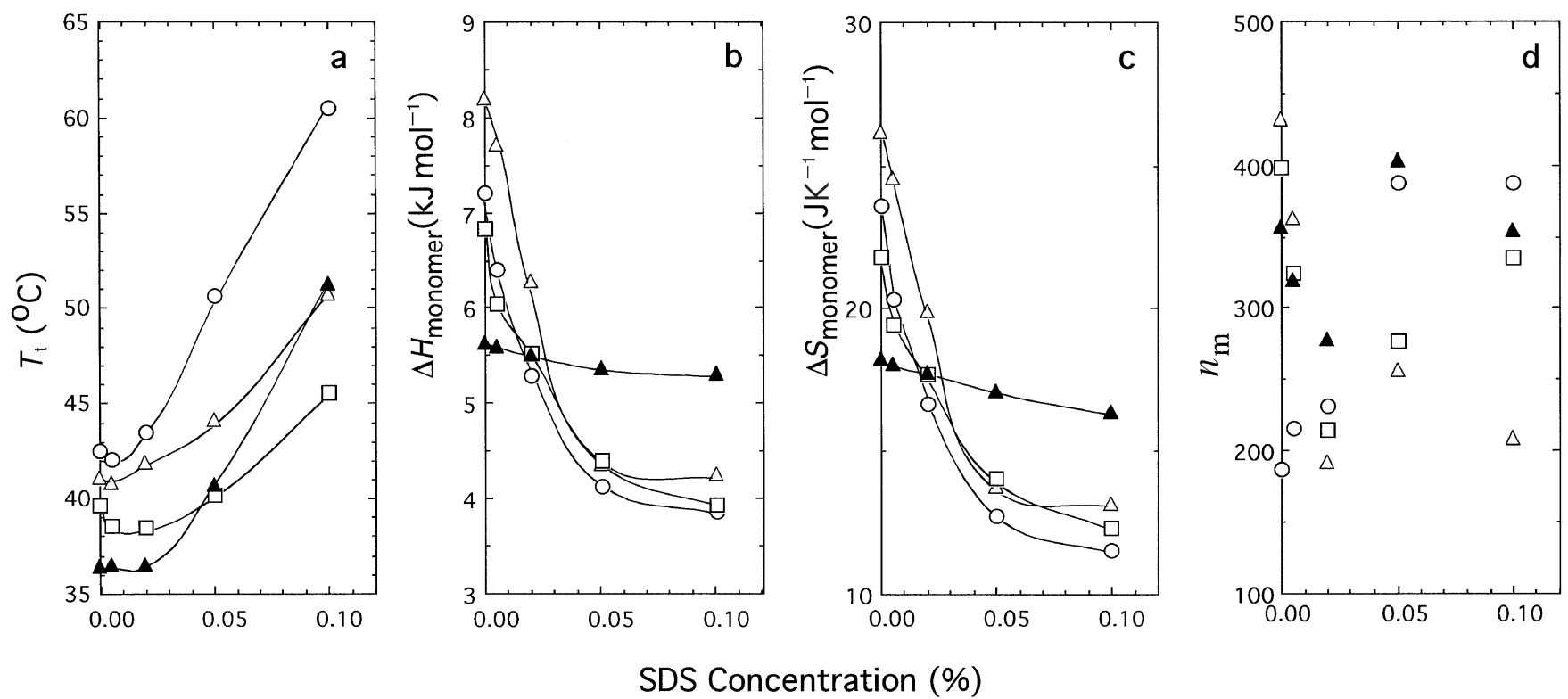

SDS Concentration (\%)

Figure 4. SDS concentration dependence of $T_{\mathrm{t}}$ (a), $\Delta H_{\text {monomer }}$ (b), $\Delta S_{\text {monomer }}$ (c), and $n_{\mathrm{m}}$ (d) for PNVIBA and PNIPAM solutions. PNVIBA: $\bigcirc, M_{\mathrm{n}}=11 \mathrm{kDa}: \triangle, M_{\mathrm{n}}=66 \mathrm{kDa}: \square, M_{\mathrm{n}}=460 \mathrm{kDa}$. PNIPAM: $\boldsymbol{\Lambda}, M_{\mathrm{n}}=49 \mathrm{kDa}$. Curves in (a)-(c) are arbitrary.

hence some intermolecular interaction will be necessary. This might be the reason of molecular weight and concentration dependence of $T_{\mathrm{t}}$, especially for shorter polymers. For samples of several hundreds $\mathrm{kDa}$ and concentrations over $0.05(\mathrm{w} / \mathrm{v}) \%$, these dependences are practically unobservable and will give almost flat phase diagrams. ${ }^{26}$

Compared with PNIPAM, PNVIBA gives larger $\Delta H$ and $\Delta S$, but the size of the cooperative domain is similar. The difference in $T_{\mathrm{t}}$ is only $15 \%$ in absolute temperature scale, but this larger $\Delta H$ value will result in the sharper transition in turbidimetric measurements, which is very important for practical applications. The origin of this $\Delta H$ is thought to be mainly the hydrogen bond cleavage at the side chain of the polymer. Thus, PNVIBA seems to be hydrated or intramolecularly hydrogen-bonded more tightly than PNIPAM. The sole difference in these two polymers is in the direction of the amide bond in the side chain, and the coordination in PNVIBA, NH being inside and $\mathrm{CO}$ being outside, closer to isopropyl group, seems to be favorable for the hydrogen bond formations with water.

With addition of SDS, both $\Delta H$ and $\Delta S$ of transition decreased. The decrements were much larger in PNVIBA and in the presence of 0.05 or $0.1(\mathrm{w} / \mathrm{v}) \%$ SDS both $\Delta H$ and $\Delta S$ became even smaller than those of PNIPAM. These changes were mostly compensated and as a result the effects of SDS addition on $T_{\mathrm{t}}$ at higher concentrations are rather larger in PNIPAM than in PNVIBA. Addition of SDS at low concentrations does little affect $T_{\mathrm{t}}$ and seems to hinder the successive aggregations of collapsed chains. The solutions PNIPAM or PNVIBA of sufficient molecular weight did not strongly become turbid in the presence of $0.02 \%$, and $T_{\mathrm{t}}$ did not show distinct change, ${ }^{12}$ which afforded the dynamic light scattering measurements, by preventing higher aggregation of the collapsed (single) chains.

The presence of very small amount of SDS in the polymer solutions destabilizes the coil state of polymer, though weakly, and the increase of SDS concentration over a certain level in turn stabilizes the coil state. During these processes, the hydrogen bonding on the polymer side chains is weakened. The entropy of the coil state is also increased, or that of the collapse state will be decreased, in order to give smaller entropy change, which is insufficient to compensate the enthalpy change. Thus the transition temperature increased drastically at high concentrations of SDS. All these results will come from the direct interactions of SDS molecules with polymer (side chain and main chain). The differences in the changes of these thermodynamic parameters in two polymers will reflect the differences in the strength of hydrogen-bonding properties of polymer side chains, and in the strength of interactions with surfactant molecules.

\section{REFERENCES}

1. M. Heskins and J. E. Guillet., J. Macromol. Sci. A-2, 1441 (1968).

2. H. G. Schild, Prog. Polym. Sci., 17, 163 (1992).

3. M. Shibayama and T. Tanaka, Adv. Polym. Sci., 109, 1 (1993).

4. Y. H. Bae, T. Okano, R. Hsu, and S. W. Kim. Makromol. Chem. Rapid Commun., 8, 481 (1987).

5. A. S. Hoffman, J. Control. Release, 6, 297 (1987).

6. A. Gustafsson, H. Wennerstrom, and F. Tjerneld, Fluid Phase Equilibr., 29, 365 (1986). 
7. M. Akashi, S. Nakano, and A. Kishida, J. Polym. Sci., Part A: Polym. Chem., 34, 301 (1996).

8. K. Suwa, Y. Wada, Y. Kikunaga, K. Morishita, A. Kishida, and M. Akashi, J. Polym. Sci., Part A: Polym. Chem., 35, 1763 (1997).

9. K. Suwa, K. Morishita, A. Kishida, and M. Akashi, J. Polym. Sci., Part A: Polym. Chem., 35, 3377 (1997).

10. S. Kunugi, K. Takano, N. Tanaka, K. Suwa, and M. Akashi, Macromolecules, 30, 4499 (1997).

11. K. Suwa, K. Yamamoto, M. Akashi, K. Takano, N. Tanaka, and S. Kunugi, Colloid Polym. Sci., 276, 529 (1998).

12. S. Kunugi, Y. Yamazaki, K. Takano, N. Tanaka, and M. Akashi, Langmuir, 15, 4056 (1999).

13. S. Kunugi, T. Tada, Y. Yamazaki, K. Yamamoto, and M. Akashi, Langmuir, 16, 2040 (2000).

14. E. I. Tiktopulo, V. E. Bychkova, J. Ricka, and O. B. Ptitsyn, Macromolecules, 27, 2879 (1994).

15. E. I. Tiktopulo, V. N. Uversky, B. B. Lushchik, S. I. Klenin, V. E. Bychkova, and O. B. Ptitsyn, Macromolecules, 28, 7518 (1995).

16. O. B. Ptitsyn, "Protein Folding”, T. E. Creighton, Ed., W. H.
Freeman, New York, N.Y., 1992, p 243.

17. S. Kunugi and N. Tanaka, Biochim. Biophys. Acta, (in press).

18. H. G. Schild and D. A. Tirrell, J. Phys. Chem., 94, 4352 (1990).

19. P. L. Privalov, "Protein Folding", T. E. Creighton, Ed., W. H. Freeman, New York, N.Y., 1992, p 83.

20. M. Meewes, M. Ricka, M. de Silva, R. Nyffenegger, and T. Binkert, Macromolecules, 24, 5811 (1991).

21. Y. Yamazaki, T. Tada, and S. Kunugi, Colloid Polym. Sci., 278, 80 (2000).

22. W. S. Cai, L. H. Gan, and K. C. Tam, Colloid Polym. Sci., 279, 793 (2001)

23. Y. Maeda, T. Higuchi, and I. Ikeda, Langmuir, 17, 7535 (2001).

24. S. Fujishige, K. Kubota, and I. Ando, J. Phys. Chem., 93, 3311 (1989).

25. S. Fujishige, K. Kubota, and I. Ando, J. Phys. Chem., 94, 5154 (1990).

26. K. Kubota, S. Fujishige, and I. Ando, Polym. J., 22, 15 (1990).

27. H. G. Schild and D. A. Tirrell, Langmuir, 7, 665 (1991). 